\title{
The impact of a brief lifestyle intervention delivered by generalist community nurses (CN SNAP trial)
}

Mark F Harris*, Bibiana C Chan, Rachel A Laws, Anna M Williams, Gawaine Powell Davies, Upali W Jayasinghe, Mahnaz Fanaian, Neil Orr, Andrew Milat and on behalf of the CN SNAP Project Team

\begin{abstract}
Background: The risk factors for chronic disease, smoking, poor nutrition, hazardous alcohol consumption, physical inactivity and weight (SNAPW) are common in primary health care (PHC) affording opportunity for preventive interventions. Community nurses are an important component of PHC in Australia. However there has been little research evaluating the effectiveness of lifestyle interventions in routine community nursing practice. This study aimed to address this gap in our knowledge.

Methods: The study was a quasi-experimental trial involving four generalist community nursing (CN) services in New South Wales, Australia. Two services were randomly allocated to an 'early intervention' and two to a 'late intervention' group. Nurses in the early intervention group received training and support in identifying risk factors and offering brief lifestyle intervention for clients. Those in the late intervention group provided usual care for the first 6 months and then received training. Clients aged 30-80 years who were referred to the services between September 2009 and September 2010 were recruited prior to being seen by the nurse and baseline self-reported data collected. Data on their SNAPW risk factors, readiness to change these behaviours and advice and referral received about their risk factors in the previous 3 months were collected at baseline, 3 and 6 months. Analysis compared changes using univariate and multilevel regression techniques.
\end{abstract}

Results: 804 participants were recruited from 2361 (34.1\%) eligible clients. The proportion of clients who recalled receiving dietary or physical activity advice increased between baseline and 3 months in the early intervention group (from 12.9 to $23.3 \%$ and 12.3 to $19.1 \%$ respectively) as did the proportion who recalled being referred for dietary or physical activity interventions (from 9.5 to $15.6 \%$ and 5.8 to $21.0 \%$ respectively). There was no change in the late intervention group. There a shift towards greater readiness to change in those who were physically inactive in the early but not the comparison group. Clients in both groups reported being more physically active and eating more fruit and vegetables but there were no significant differences between groups at 6 months.

Conclusion: The study demonstrated that although the intervention was associated with increases in advice and referral for diet or physical activity and readiness for change in physical activity, this did not translate into significant changes in lifestyle behaviours or weight. This suggests a need to facilitate referral to more intensive long-term interventions for clients with risk factors identified by primary health care nurses.

Trial registration: ACTRN12609001081202

Keywords: Primary health care, Lifestyle behaviours, Smoking, Nutrition, Alcohol, Physical activity, Community nursing

\footnotetext{
* Correspondence: m.f.harris@unsw.edu.au

Centre for Primary Health Care and Equity, School of Public Health and

Community Medicine, University of New South Wales, Sydney, NSW 2052,

Australia
}

\section{Biomed Central}

(c) 2013 Harris et al.; licensee BioMed Central Ltd. This is an Open Access article distributed under the terms of the Creative Commons Attribution License (http://creativecommons.org/licenses/by/2.0), which permits unrestricted use, distribution, and reproduction in any medium, provided the original work is properly cited. 


\section{Background}

In Australia, chronic diseases such as heart disease and diabetes are the leading causes of death and disability [1]. The risk factors for these conditions include risk behaviours (in smoking, nutrition, alcohol and physical activity) and overweight (SNAPW). These are prevalent in the community, with over $90 \%$ of adults not consuming the recommended five serves of vegetables per day, over half not consuming adequate amounts of fruit, $62 \%$ overweight or obese, one third, physically inactive, one in five smoke and $21 \%$ drink alcohol at levels which pose a risk to their health [2].

Primary health care (PHC) is an important setting for addressing lifestyle risk factors because of its accessibility, continuity, and comprehensiveness of the care provided [3]. There is evidence that clients expect to receive lifestyle intervention from PHC clinicians [4]. Lifestyle interventions delivered in $\mathrm{PHC}$ are effective in helping clients to stop smoking [5], reduce 'at-risk alcohol' consumption [6], improve weight, diet and physical activity levels [7-12]. The 5As (assess, advise (including motivational interviewing) and agree on goals, assist (including referral), and arrange (follow up) have been developed as a framework for addressing these risk factors in clinical practice [13,14].

In NSW, generalist community nurses frequently see clients in their own home, providing care for patients recently discharged from hospital, the aged and those with chronic diseases. Although the traditional community nursing model of practice includes health promotion activities, community nursing services have increasingly tended to provide shorter term more clinically focused services to individual clients $[15,16]$. Our previous research has shown that community health nurses consider the provision of lifestyle intervention appropriate to their role and it is well accepted by clients [17]. However, few studies have evaluated the effectiveness of lifestyle interventions provided by community nurses in routine practice [18-21]. The aim of this study was to evaluate the impact of a brief lifestyle intervention delivered by community health nurses as part of their routine practice on changes in clients' SNAPW risk factors.

\section{Methods}

\section{Study design and setting}

This study was conducted in four general community nursing services in New South Wales, Australia. Services were recruited via an expression of interest mailed to all Area Health Services (AHS) in NSW $(\mathrm{n}=8)$. The design was quasi-experimental, with the services randomly allocated to an 'early intervention' (EI) group or 'late intervention' (LI) (comparison) group. EI services were provided with training and support for nurses in identifying clients with high risk and offering brief SNAPW intervention during routine consultations. The protocol for the study has been previously described [22].

\section{Intervention}

The intervention was designed and implemented on two levels: (a) service level and (b) client level.

\section{Service-level intervention}

The service-level intervention was delivered by University staff and consisted of four components:

- A 1-day training program in the assessment and management of the SNAPW risk factors (including motivational interviewing) for participating community nurses delivered by the research team in conjunction with local providers. The training included the use of role-plays with simulated clients (actors), group discussions and activities;

- Integration of standardised screening tools and prompts for SNAPW risk factors into the service-specific assessment processes used by the nurses in the management of clients;

- Development and distribution of a local service referral directory to each community nursing team to promote referral of clients for ongoing specialist management or more / ongoing intensive lifestyle intervention; and

- Provision of client resources to all participating nurses. The resources included a written guide for nurses, written action plans for use with clients on each SNAPW risk factor, tape measures for measuring waist circumference and pedometers for loan to clients to encourage self-monitoring of physical activity.

A nurse from each of the EI sites was seconded to work with the research team to develop the intervention and to support its implementation at the local level.

\section{Client-level intervention}

The client-level intervention was provided by the participating nurses. The goals of the clinical intervention were to achieve and maintain lifestyle changes consistent with current Australian recommendations [23]:

- Moderate physical activity for at least 30 minutes/ day, including walking, jogging, swimming, aerobic activity, ball games, skiing, with circuit-type resistance training if possible, twice a week;

- A diet low in saturated fats, sucrose and salt with increased portions of vegetables and fruit per day (up to seven portions) in order to achieve a diet where the percentage of energy from carbohydrates $=50 \%$, saturated fats $<10 \%$ (and total fats $<30 \%$, protein $1 \mathrm{~g} / \mathrm{kg}$ ideal body weight per day, fibre $15 \mathrm{~g} / 1000 \mathrm{kcal}$ ); 
- Weight reduction (if overweight) of $\geq 5 \mathrm{~kg}$ or $5 \%$ of body weight;

- Smoking cessation (if smoker);

- Limit alcohol intake (if drinking) to $\leq 2$ drinks / day, including 1-2 alcohol-free days/week.

The nurses assessed clients' lifestyle risk factors and then provided brief educational intervention tailored to their readiness to change, based on the 5As Model [3] (Figure 1), for one or more SNAPW risk factors. This occurred over two or more visits. Clients who were 'at risk' (those who were obese, smoked or who had multiple risk behaviours or illnesses arising from them) and who were in the contemplation or action stages of change were referred to specialist providers for more intensive intervention.

\section{Late intervention}

Two of the four $\mathrm{CN}$ services were randomly allocated to the LI group. Late intervention services provided usual care for 18 months. After all data ad been collected the service level intervention was introduced into these services as well.

\section{Client recruitment}

Between September 2009 and September 2010 clients who met the selection criteria and who had been referred to participating services (Table 1) were invited to participate in the study. Potential participants were contacted by phone on the day of referral (where possible) by trained local recruitment officers. The client recruitment process is outlined in Figure 2.

\section{Study outcomes, measurements and data collection}

The study outcomes, measurement tools and timeframe for data collection are summarised in Table 2. The measurement tools were validated in other research [24-26]. The diet, physical activity, alcohol and weight outcomes were continuous measures. Diet score was the total number of serves of fruit and vegetables per day up to a maximum of 7 . The physical activity score combined

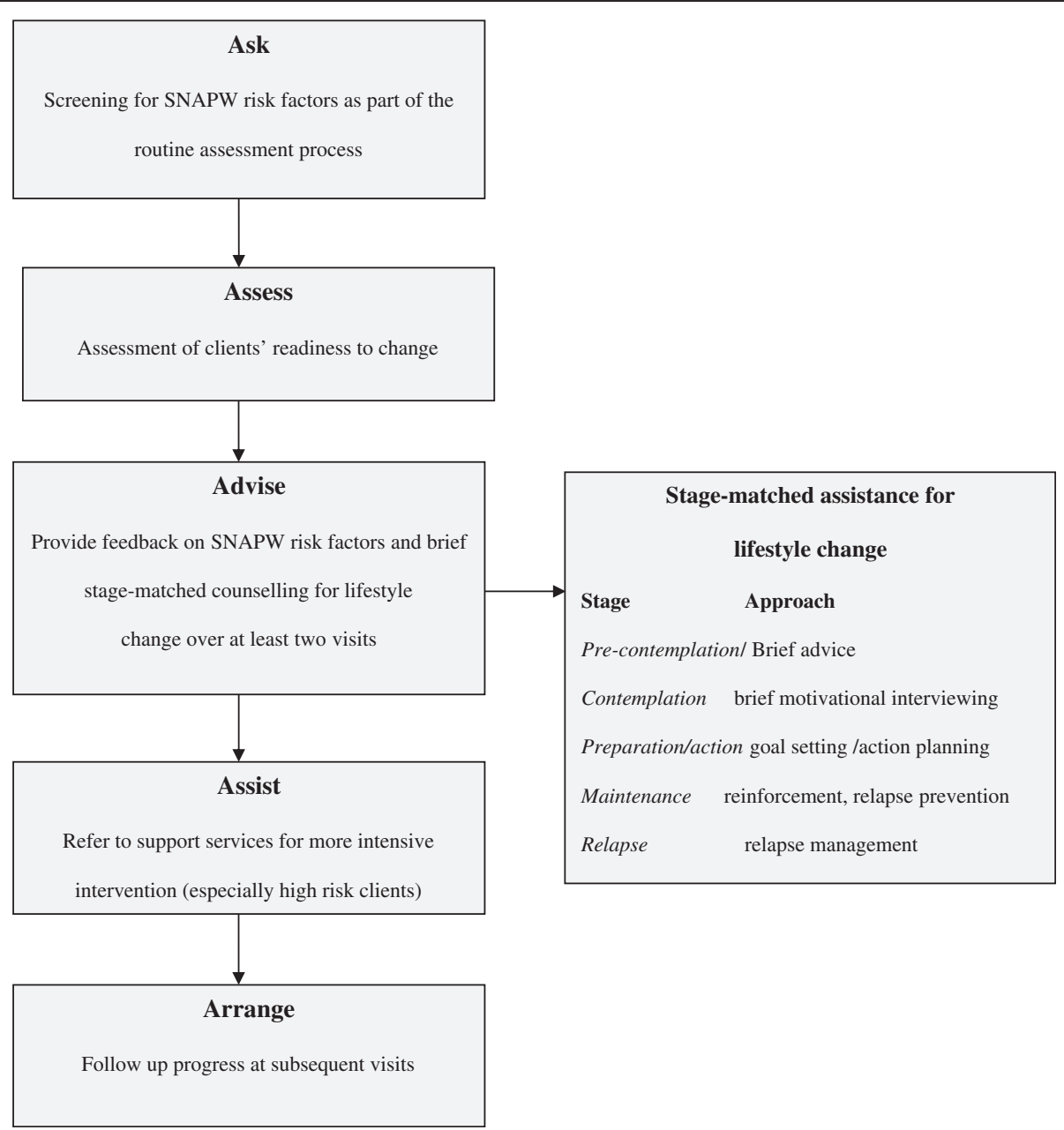

Figure 15 As model of brief lifestyle intervention. 
Table 1 Selection criteria for recruiting clients to participate in the trial

\begin{tabular}{|c|c|}
\hline Types & Selection criteria \\
\hline \multirow[t]{3}{*}{ Inclusion criteria } & * Clients referred to community nursing services \\
\hline & * Age 30-80 years \\
\hline & $\begin{array}{l}\text { * Able to read and understand English at a level that enables the client to participate in a } \\
\text { telephone-administered survey and to understand the participant information sheet. }\end{array}$ \\
\hline \multirow[t]{6}{*}{ Exclusion criteria } & * Palliative care clients. \\
\hline & * Clients receiving only one- visit or occasion of service. \\
\hline & * Clients with significant cognitive impairment (unable to complete telephone-administered survey). \\
\hline & $\begin{array}{l}\text { * Clients currently receiving help in changing their lifestyle from a health professional (other than their GP) } \\
\text { such as a dietitian or exercise physiologist. }\end{array}$ \\
\hline & $\begin{array}{l}\text { * Clients currently attending a chronic disease management program such as cardiac rehabilitation, } \\
\text { diabetes education program. }\end{array}$ \\
\hline & $\begin{array}{l}\text { * Clients who have attended the generalist community nursing service in the previous } 6 \text { months } \\
\text { (and therefore may have already received lifestyle intervention). }\end{array}$ \\
\hline
\end{tabular}

assessment of duration of vigorous and moderate physical activity (scored 0-8, <4 considered at risk) [27]. Alcohol was the average number of standard drinks per day. Smoking status was a categorical variable (smoker or non-smoker). Mediator variables included change in clients' 'readiness to change' lifestyle behaviours [28]. Process measures included change in clients' recall of advice or referral over the previous 3 months. Data were collected from a 15-minute telephone-administered survey conducted with clients at baseline (prior to first nurse visit) and at 3 and 6 months. The telephone survey was conducted by trained independent data collectors blinded to the group allocation (EI or LI) groups.

\section{Statistical analysis \\ Power and sample size calculation}

The a priori sample size was 400 clients per group $(n=800)$. This was calculated based on estimates of

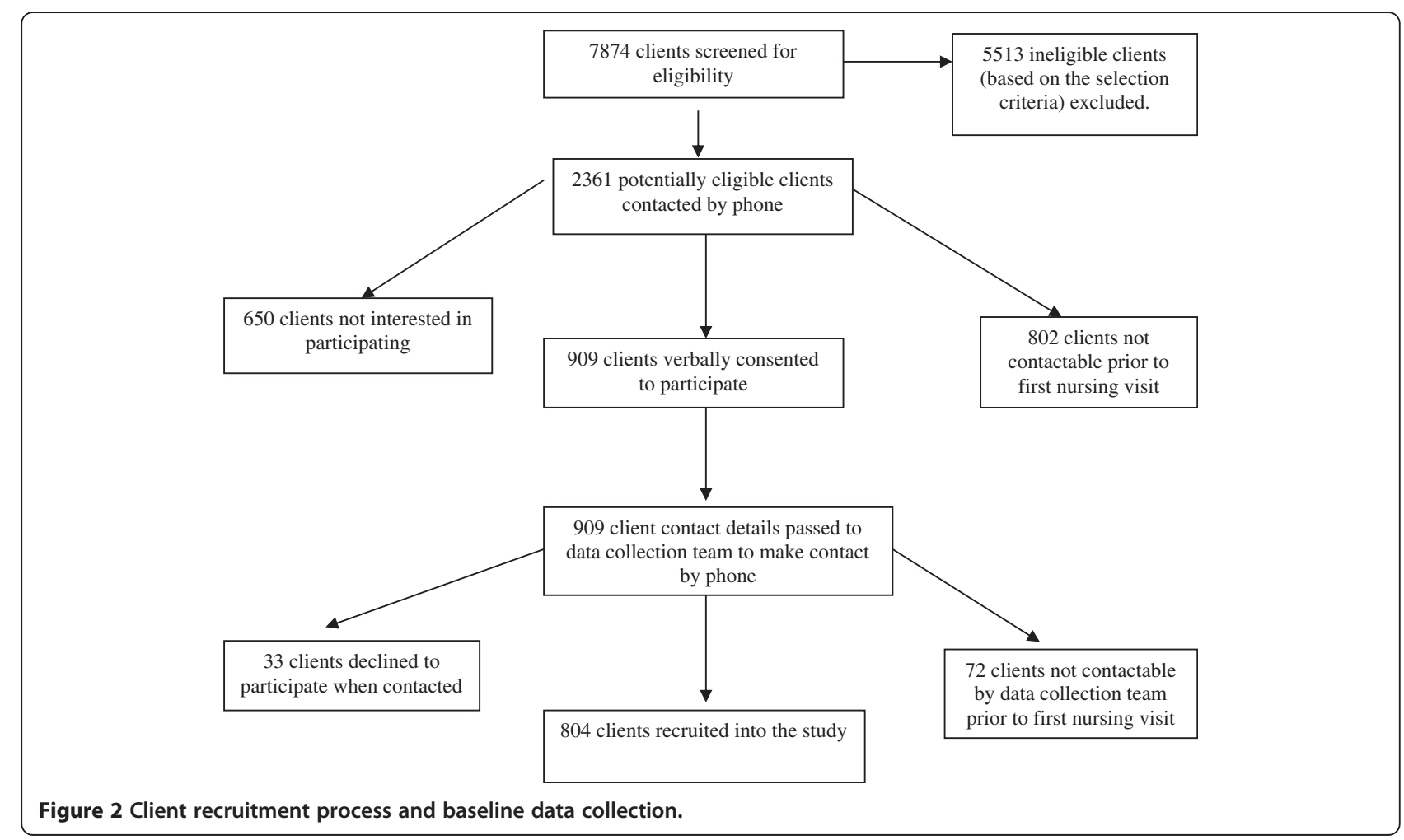


Table 2 Study outcomes and measurement

\begin{tabular}{ll}
\hline Outcomes & Measurement \\
\hline Change in mean physical activity score & Brief validated physical activity tool [24] \\
Change in mean alcohol intake score & Validated AUDIT-C tool [25] \\
Mean weight change & Validated questions from the NSW Health survey [26] \\
Change in smoking status & Self report \\
Change in adequate levels of physical activity & Self report \\
Change in 'at risk' alcohol consumption & Self report \\
Change consumption of $>=2$ serves of fruit per day & Self report \\
Change in consumption of $>=5$ serves of vegetables per day & Self report \\
Progression in stages of change & Self report \\
At risk clients offered evidence-based advice to modify their risk factors & On five point intentions scales [28] \\
At risk clients offered evidence-based referral to modify their risk factors & Recall over previous 3 months \\
\hline
\end{tabular}

Collected by client telephone survey at baseline, 3 and 6 months.

change in mean risk scores of self-reported measures of lifestyle risk factors. This was sufficient based on a standard deviation from previous research [29], design effect of 1.8 and loss to follow up of $20 \%$ to detect the following changes in mean risk scores:-

- 1 portion of fruit and vegetables per day (based on sd 2.02)

- 1 unit of physical activity score (based on sd 2.13)

- $5 \mathrm{~kg}$ of self-reported weight loss (based on sd 14.95)

\section{Analysis}

Univariate comparisons were made within group between baseline and 3 months and between groups for receipt of advice and referral. Change in readiness to change was categorised at 6 months and compared between groups. Statistical tests included $t$ test for continuous variables and chi square test for categorical variables.

Change in clients' lifestyle risk factors between the EI and LI (comparison) groups were evaluated using multilevel models which included a number of patient level covariates thought to possibly influence the outcomes [30]. Three repeated measures of SNAPW were compared within clients [31]. Multilevel linear regression analysis was conducted on physical activity score, diet score and weight. In the first model three levels were fitted which included: service (level 3), client (level 2) and time (level 1). The variance between services was found not to be significant. For each risk factor at 6 months, a two level regression model was fitted. This included the time and client as levels adjusting for baseline risk, intervention, linear time $(0=$ baseline; $1=3$ months; $2=6$ months $)$, gender, age, employment status, reason for referral, mental health and physical health status, number of risk factors and physical limitation. The multilevel statistical models were fitted using MLwiN version 2.25 [32].

\section{Ethics}

The project was approved by the Hunter New England Human Research Ethics Committee (Ref No 08/10/15/4.03), and ratified by the University of New South Wales Human Research Ethics Committee (HREC) and the Human Research Ethics Committees in each of the participating Area Health Services. The study was conducted in compliance with this Committees regulations and the Helsinki declaration. All participants provided full informed written consent for publication of findings from this research.

\section{Results}

\section{Baseline characteristics}

A total of 804 clients were recruited from 2361 potentially eligible clients (34.1\%), 425 in the EI group and 379 in the LI group (Figure 2). Just under half (49.3\%) were female, $67.1 \%$ were 60 years of age or over and $53.1 \%$ were retired from paid work. Few participants spoke a language other than English or were of Aboriginal or Torres Strait Islander descent (Table 3). There were no significant differences in age and gender between those who accepted and those who declined to participate or between those in the EI and LI groups (Table 3).

The majority (61.6\%) of clients rated their own health as 'good, very good or excellent' and $12.7 \%$ reported that during the past month they had felt 'downhearted or blue' most or all of the time. Almost all clients (97.6\%) had at least one lifestyle risk factor and 101 (12.5\%) had at least four (Table 3). At baseline 17.2\% of participants reported being smokers, $78.5 \%$ had insufficient fruit and vegetable dietary intake, $74.0 \%$ were overweight or obese, $36.9 \%$ had at risk drinking levels. Of those who were able to engage in physical activity, $50.5 \%$ had inadequate levels. There were no significant differences between those in the EI and LI groups (Table 3). 
Table 3 Characteristics of CN SNAPW trial clients at baseline

\begin{tabular}{|c|c|c|c|c|c|c|}
\hline \multirow[t]{2}{*}{ Characteristics } & \multicolumn{2}{|c|}{ Total $(n=804)$} & \multicolumn{2}{|c|}{ Early interv $(n=425)$} & \multicolumn{2}{|c|}{ Late interv (379) } \\
\hline & $\mathbf{N}$ & $\%$ & $\mathbf{N}$ & $\%$ & $\mathbf{N}$ & $\%$ \\
\hline Female & 396 & 49.3 & 214 & 50.4 & 182 & 48.0 \\
\hline Aboriginal/ Torres Strait Islander & 4 & 0.5 & 2 & 0.5 & 2 & 0.5 \\
\hline Language other than English & 35 & 4.4 & 18 & 4.2 & 17 & 4.5 \\
\hline Employed & 215 & 26.7 & 115 & 27.1 & 100 & 26.4 \\
\hline Unable to work (long-term sickness/ disability) & 109 & 13.6 & 50 & 11.8 & 59 & 15.6 \\
\hline Retired from paid work & 419 & 53.1 & 229 & 53.9 & 190 & 50.1 \\
\hline \multicolumn{7}{|l|}{ Age (yrs) } \\
\hline $30-39$ yrs & 44 & 5.5 & 22 & 5.2 & 22 & 5.8 \\
\hline $40-49$ & 78 & 9.7 & 44 & 10.4 & 34 & 9.0 \\
\hline $50-59$ & 142 & 17.7 & 76 & 18.0 & 66 & 17.4 \\
\hline 60-69 & 256 & 31.9 & 136 & 32.2 & 120 & 31.7 \\
\hline$\geq 70$ & 280 & 35.2 & 143 & 34.3 & 137 & 36.1 \\
\hline Self-rated health status Poor or Fair & 308 & 38.3 & 158 & 37.2 & 150 & 39.6 \\
\hline \multicolumn{7}{|c|}{ Self-rated mental health status: Downhearted or blue } \\
\hline Most to all of the time & 102 & 12.7 & 49 & 11.5 & 53 & 14.0 \\
\hline \multicolumn{7}{|l|}{ Health conditions } \\
\hline Hypertension & 395 & 49.1 & 225 & 52.9 & 170 & 44.9 \\
\hline Arthritis & 277 & 34.5 & 155 & 36.5 & 122 & 32.2 \\
\hline High cholesterol & 239 & 29.7 & 132 & 31.1 & 107 & 28.2 \\
\hline Cancer & 213 & 26.5 & 123 & 28.9 & 90 & 23.7 \\
\hline Diabetes & 185 & 23.0 & 102 & 24.0 & 83 & 21.9 \\
\hline Depression & 132 & 16.4 & 66 & 15.5 & 66 & 17.4 \\
\hline Heart disease & 132 & 16.4 & 55 & 15.9 & 55 & 17.1 \\
\hline no risk factors & \multicolumn{2}{|c|}{$18(2.2 \%)$} & \multicolumn{2}{|c|}{$11(2.6 \%)$} & \multicolumn{2}{|c|}{$7(1.8 \%)$} \\
\hline 1 risk only & \multicolumn{2}{|c|}{$147(18.3 \%)$} & \multicolumn{2}{|c|}{$76(17.9 \%$} & \multicolumn{2}{|c|}{$71(18.7 \%)$} \\
\hline 2 risks & \multicolumn{2}{|c|}{$328(40.2 \%)$} & \multicolumn{2}{|c|}{$164(38.6 \%)$} & \multicolumn{2}{|c|}{$159(42.0 \%)$} \\
\hline 3 risks & \multicolumn{2}{|c|}{$215(26.7 \%)$} & \multicolumn{2}{|c|}{$120(28.2$} & \multicolumn{2}{|c|}{$95(25.1 \%)$} \\
\hline 4 risks & \multicolumn{2}{|c|}{$92(11.4 \%)$} & \multicolumn{2}{|c|}{$50(11.8 \%)$} & \multicolumn{2}{|c|}{$42(11.1 \%)$} \\
\hline 5 risks & \multicolumn{2}{|c|}{$9(1.1 \%)$} & \multicolumn{2}{|c|}{$4(0.9)$} & \multicolumn{2}{|c|}{$5(1.3)$} \\
\hline$<2$ serves of fruit $(n=801)$ & \multicolumn{2}{|c|}{$336(41.9 \%)$} & & & & 7\%) \\
\hline$<5$ serves of veg $(n=796)$ & & & & & & 4\%) \\
\hline At risk alcohol consumption ${ }^{\mathrm{a}}(\mathrm{n}=804)$ & & 9\%) & & & & 4\%) \\
\hline Smokers $(\mathrm{n}=802)$ & & & & & & \\
\hline Overweight (OW) $(n=785)$ & & 5\%) & & & & 6\%) \\
\hline Obese $(n=785)$ & & 5\%) & & & & 6\%) \\
\hline OW or obese $(n=785)$ & & $0 \%)$ & & & & 8\%) \\
\hline Unable to do physical activity $(P A)^{b}(n=793)$ & & 3\%) & & & & 2\%) \\
\hline Able to do PA but inadequate $(n=418)$ & & 5\%) & & & & \\
\hline
\end{tabular}

\footnotetext{
${ }^{a}$ The 2009 national alcohol guidelines for alcohol consumption are available at: http://www.health.gov.au/internet/alcohol/publishing.nsf/Content/guide-adult. ${ }^{b}$ Those with major physical limitations which (a) limited their ability to engage in physical activity a lot and (b) were estimated to last for more than 4 weeks, or unsure.
} 
Recall of lifestyle advice and referrals of clients identified with lifestyle risk factors at baseline and 3 months Only a minority of participants with a SNAPW risk factor recalled having received advice from any source in the 3 months prior to the baseline survey. There was no difference between the EI and LI groups in this measure. However, in the EI sites the overall percentage of clients who reported having received advice from any source at 3 months increased significantly for dietary advice (from $12.9 \%$ at baseline to $23.3 \%$ at 3 months) and physical activity advice (from $12.5 \%$ at baseline to $19.1 \%$ at 3 months). There were no significant changes in the LI sites and at 3 months the early intervention group was more likely to report having received diet advice (Table 4).

There were significant increases in reported referrals for diet, physical activity and alcohol from baseline to 3 months in the EI group (from 9.5 to $15.6 \%, 5.8$ to $21.0 \%$ and 1.2 to $6.9 \%$ respectively). There was no change in the LI group (Table 4). There were no significant differences between groups at three months.

\section{'Readiness to change' of clients identified with lifestyle risk factors}

At baseline, the majority of clients who were at risk were in the contemplation, preparation or action stages of change for weight change, physical activity, improved nutrition or smoking $(65 \%, 67 \% 59.4 \%$, and $73 . \%$ respectively). However, only a minority of those with at-risk alcohol consumption were in the contemplation, preparation or action phases (48.1\%). At 6 months there was a significantly greater shift towards higher stages of change in those who were physically inactive, in the EI group compared to the LI group $(58.8 \%$ vs 27.8\%; Chi square $=4.54, p=0.032)$, Table 5. Readiness to change smoking increased in LI but not the EI group. There were no other significant changes in either group.

\section{Client self-reported risk factors}

Overall, there were no significant differences in risk factors between EI and LI groups at baseline, 3 or 6 months.

However, there were significant increases in diet scores and physical activity between baseline and 3 months and baseline and 6 months in both groups (Table 6). There were no significant changes in smoking, alcohol or self-reported weight.

Multilevel regression analysis showed that being retired had a positive effect on diet (Table 7). Self-reported health had a positive effect on physical activity score. Males, young, unemployed, those with good mental health and poor general health tended to have a negative effect on

Table 4 Proportion of at risk clients recalling being offered advice or being referred to manage risk factors

\begin{tabular}{|c|c|c|c|c|}
\hline & \multicolumn{2}{|l|}{ Baseline } & \multicolumn{2}{|l|}{3 months } \\
\hline & Early intervention & Late intervention & Early intervention & Late intervention \\
\hline & $\mathrm{n} / \mathrm{N}$ & $\mathrm{n} / \mathrm{N}$ & $\mathrm{n} / \mathrm{N}$ & $n / N$ \\
\hline & $\%,(95 \% \mathrm{Cl})$ & $\%,(95 \% \mathrm{Cl})$ & $\%,(95 \% \mathrm{Cl})$ & $\%,(95 \% \mathrm{Cl})$ \\
\hline \multicolumn{5}{|l|}{ Offered advice from any provider } \\
\hline \multirow[t]{2}{*}{ Diet } & $33 / 256$ & $31 / 253$ & $60 / 257$ & $40 / 247$ \\
\hline & $12.9 \%(8.6-17.0)$ & $12.3 \%(8.2-16.3)$ & $23.3(18.1-28.5)^{*} \#$ & $16.2 \%(11.6-20.8)$ \\
\hline \multirow[t]{2}{*}{ Physical activity (for those able to engage in PA) } & $15 / 120$ & $8 / 91$ & $35 / 183$ & $20 / 162$ \\
\hline & $12.5 \%(6.6-18.4)$ & $8.8 \%(3.0-14.6)$ & $19.1 \%(13.4-24.8)^{*}$ & $12.3 \%(7.3-17.4)$ \\
\hline \multirow[t]{2}{*}{ Smoking } & $10 / 64$ & $16 / 65$ & $11 / 46$ & $11 / 47$ \\
\hline & $15.6 \%(6.7-24.5)$ & $24.6 \%(14.1-35.1)$ & $23.9 \%(11.6-36.2)$ & $23.4 \%(11.3-35.5)$ \\
\hline \multirow[t]{2}{*}{ Alcohol } & $6 / 105$ & $6 / 93$ & $6 / 84$ & $9 / 75$ \\
\hline & $5.7 \%(1.3-10.2)$ & $6.5 \%(1.5-11.4)$ & $7.1 \%(1.6-12.7)$ & $12.0 \%(4.7-19.4)$ \\
\hline \multicolumn{5}{|l|}{ Referral for SNAP intervention } \\
\hline \multirow[t]{2}{*}{ Diet } & $31 / 326$ & $19 / 298$ & $40 / 257$ & $29 / 252$ \\
\hline & $9.5 \%(6.3-12.7)$ & $6.4 \%(3.6-9.2)$ & $15.6 \%(11.0-20.0)^{*}$ & $11.5 \%(7.6-15.5)$ \\
\hline \multirow[t]{2}{*}{ Physical activity (for those able to engage in PA) } & $7 / 120$ & $5 / 91$ & $21 / 100$ & $9 / 78$ \\
\hline & $5.8 \%(1.6-10.0)$ & $5.5 \%(0.8-10.2)$ & $21.0 \%(13.0-30.0)^{*}$ & $11.5 \%(4.5-18.6 \%)$ \\
\hline \multirow[t]{2}{*}{ Smoking } & $8 / 74$ & $11 / 64$ & $9 / 62$ & $10 / 49$ \\
\hline & $10.8 \%(3.7-17.9)$ & $17.2 \%(7.9-26.4)$ & $14.5 \%(5.8-23.3)$ & $20.4 \%(9.1-31.7)$ \\
\hline \multirow[t]{2}{*}{ Alcohol } & $3 / 159$ & $4 / 138$ & $9 / 131$ & $6 / 109$ \\
\hline & $1.2 \%(0-4.0)$ & $2.9 \%(0.1-5.7)$ & $6.9 \%(2.5-11.2) *$ & $5.5 \%(1.2-9.8)$ \\
\hline
\end{tabular}

* Significant change from baseline $\mathrm{p}<0.05$

\# Significant difference between groups $\mathrm{p}<0.05$. 
Table 5 Shift to higher change stage between baseline and 6 months for clients with SNAPW risk factors

\begin{tabular}{|c|c|c|c|c|c|c|c|c|c|c|}
\hline \multirow{2}{*}{$\begin{array}{l}\text { Clients with SNAPW risk factors } \\
\text { Intervention site }\end{array}$} & \multicolumn{2}{|c|}{$\begin{array}{l}\text { Increase fruit and } \\
\text { vegetable intake }\end{array}$} & \multicolumn{2}{|c|}{$\begin{array}{c}\text { Increase physical } \\
\text { activity }\end{array}$} & \multicolumn{2}{|c|}{$\begin{array}{l}\text { Reduce alcohol } \\
\text { consumption }\end{array}$} & \multicolumn{2}{|c|}{$\begin{array}{c}\text { Reduce or } \\
\text { quit smoking }\end{array}$} & \multicolumn{2}{|c|}{$\begin{array}{l}\text { Reduce } \\
\text { weight }\end{array}$} \\
\hline & $\mathrm{El}$ & $\mathrm{LI}$ & El & $\mathrm{LI}$ & $\mathrm{El}$ & $\mathrm{LI}$ & $\mathrm{El}$ & $\mathrm{LI}$ & $\mathrm{El}$ & $\mathrm{LI}$ \\
\hline & $n=101$ & $n=105$ & $n=34$ & $n=18$ & $n=57$ & $n=42$ & $n=24$ & $n=18$ & $n=96$ & $\mathrm{n}=97$ \\
\hline Did not shift to a higher stage of change & $66.3 \%$ & $61.9 \%$ & $41.2 \%$ & $72.2 \%$ & $80.7 \%$ & $81.0 \%$ & $70.8 \%$ & $44.4 \%$ & $64.6 \%$ & $55.7 \%$ \\
\hline Shifted to a higher stage of change & $33.7 \%$ & $38.1 \%$ & $58.8 \%$ & $27.8 \%$ & $19.3 \%$ & $19.0 \%$ & $29.2 \%$ & $55.6 \%$ & $35.4 \%$ & $44.3 \%$ \\
\hline \multirow[t]{2}{*}{ Chi square (one-sided) } & \multicolumn{2}{|c|}{0.439} & \multicolumn{2}{|c|}{4.54} & \multicolumn{2}{|c|}{0.001} & \multicolumn{2}{|c|}{2.973} & \multicolumn{2}{|c|}{1.60} \\
\hline & \multicolumn{2}{|c|}{$p=0.303$} & \multicolumn{2}{|c|}{$p=0.032$} & \multicolumn{2}{|c|}{$p=0.593$} & \multicolumn{2}{|c|}{$p=0.080$} & \multicolumn{2}{|c|}{$p=0.132$} \\
\hline
\end{tabular}

Bolded figures represent significant differences between the sites.

weight loss. The intervention was not significantly related to diet score, physical activity score and weight at 6 months (Table 7). The multilevel regression model explained $16 \%$ and $42 \%$ respectively of the total client variance in the diet and physical activity scores respectively.

\section{Discussion}

This study demonstrated that community health nurses were able to implement lifestyle risk factor management as part of normal clinical practice. This individual support within PHC can complement broader population health approaches as part of a comprehensive approach to reducing cardiovascular risk factors across the population. Community health nurses are particularly well placed to deliver lifestyle interventions to high risk clients, many of whom have chronic disease and multiple behavioural risk factors.

The intervention was associated with an increase in the provision of brief diet and physical activity advice by community nurses. In qualitative interviews we found that this was a feasible addition to routine practice by the nurses which clients found acceptable [33,34]. Whilst referrals were infrequent at baseline they increased following the intervention for diet and alcohol and physical activity in the EI but not the LI groups.

Despite modest improvements in preventive care, and some shift in readiness to change physical activity, there was no evidence of a significant impact of the intervention on the SNAP behaviours or weight of clients. It may be that brief interventions from community nurses is not sufficient to achieve change in lifestyle risk factors in this group of clients, many of whom were older, had existing chronic conditions, or were recovering from acute illness. An important factor may also be that many clients were seen following discharge from hospital, and the immediate post-acute phase might not be conducive to making lifestyle change. The intervention and follow-up period in this study was relatively short and it is possible that clients might have been able to make changes once they were fully recovered. These clients may require referral onwards to more intensive interventions at an appropriate time. This requires systems to be in place for assessment of readiness to change and referral to other services. However, this was not captured in the study.

Our negative findings are in contrast with other research in the effectiveness of brief lifestyles interventions in the PHC setting. Most of that research has been conducted in family practice, in services where the nurses were involved in the care of the clients in an ongoing way, or involved major input from referral programs or providers outside PHC [35-38]. However, only a minority of clients of community health nurses in this study received care for longer than 6 months. As has been noted, in the short term many clients had reduced capacity for physical activity because of their illness. Thus while community nurses have the opportunity to assess and initiate behavioural interventions, these need to be provided in the context of long-term care.

Another possible contributor to the negative finding may be related to the relatively high proportion of patients

Table 6 SNAP risk factors scores at baseline, 3 and 6 months

\begin{tabular}{|c|c|c|c|c|c|c|c|c|}
\hline & \multicolumn{2}{|c|}{ Number } & \multicolumn{2}{|l|}{ Baseline } & \multicolumn{2}{|l|}{3 months } & \multicolumn{2}{|l|}{6 months } \\
\hline & Early & Late & $\begin{array}{l}\text { Early mean } \\
95 \% \mathrm{Cl}\end{array}$ & $\begin{array}{l}\text { Late mean } \\
95 \% \mathrm{Cl}\end{array}$ & $\begin{array}{l}\text { Early mean } \\
95 \% \mathrm{Cl}\end{array}$ & $\begin{array}{l}\text { Late mean } \\
95 \% \mathrm{Cl}\end{array}$ & $\begin{array}{l}\text { Early mean } \\
95 \% \mathrm{Cl}\end{array}$ & $\begin{array}{l}\text { Late mean } \\
95 \% \mathrm{Cl}\end{array}$ \\
\hline Diet score ${ }^{a}$ & 195 & 201 & $3.98(3.76-4.20)$ & $3.98(3.77-4.19)$ & $4.48 *(4.20-4.76)$ & $4.30^{*}(4.03-4.57)$ & $4.44 *(4.16-4.72)$ & $4.54^{*}(4.23-4.85)$ \\
\hline Physical activity score ${ }^{b}$ & 60 & 42 & $1.73(1.39-2.07)$ & $1.40(0.99-1.81)$ & $2.32^{*}(1.87-2.77)$ & $2.48^{*}(1.86-3.10)$ & $2.63^{*}(2.15-3.11)$ & $2.74^{*}(2.06-3.42)$ \\
\hline Weight (overweight) & 77 & 104 & $81.0(78.9-83.1)$ & $80.3(78.3-82.3)$ & 80.7 (78.2-83.2) & $80.4(78.1-82.7)$ & $81.0(78.5-83.5)$ & $81.7(79.4-84.0)$ \\
\hline Weight (obese) & 112 & 82 & $101.4(97.8-105.1)$ & $102.3(98.4-106.3)$ & $100.4(96.6-104.2)$ & $102.3(96.8-107.8)$ & $100.3(96.7-103.9)$ & $101.6(97.1-106.1)$ \\
\hline
\end{tabular}

* Significant difference from baseline.

${ }^{\text {a }}$ Total number of serves of fruit and vegetables per day up to maximum of 7 .

${ }^{b}$ scored $0-8,<4$ considered at risk. 
Table 7 Diet and physical activity scores and weight: multilevel regression models

\begin{tabular}{|c|c|c|c|c|c|c|}
\hline \multirow[b]{2}{*}{ Diet Score (F \& V Serves) } & \multicolumn{2}{|c|}{ Diet score } & \multicolumn{2}{|c|}{ Physical activity score } & \multicolumn{2}{|c|}{ Weight } \\
\hline & beta & SE & beta & SE & beta & SE \\
\hline Time (1,2,3 =0, 3 and 6 months) & 0.039 & 0.044 & 0.003 & 0.077 & -0.107 & 0.298 \\
\hline Intervention (early) & -0.178 & 0.125 & 0.032 & 0.146 & 0.142 & 2.13 \\
\hline Male & -0.776 & 0.110 & 0.195 & 0.133 & $5.376^{\dagger}$ & 1.605 \\
\hline Age (BL) & 0.006 & 0.007 & 0.002 & 0.008 & $-0.548^{\dagger}$ & 0.090 \\
\hline Employed & 0.206 & 0.170 & 0.227 & 0.224 & $-13.30^{\dagger}$ & 2.300 \\
\hline Retired & $0.420^{*}$ & 0.177 & -0.157 & 0.244 & 2.052 & 2.460 \\
\hline Wound management & -0.134 & 0.229 & 0.279 & 0.242 & -1.013 & 3.708 \\
\hline Catheter/incontinence & 0.055 & 0.399 & 0.052 & 0.468 & -6.318 & 6.884 \\
\hline General post hospital care & 0.144 & 0.315 & 0.647 & 0.354 & 6.700 & 4.874 \\
\hline Other & -0.334 & 0.281 & 0.395 & 0.321 & 1.521 & 4,522 \\
\hline Mental health - good & -0.240 & 0.133 & -0.07 & 0.169 & $5.938^{* *}$ & 1.917 \\
\hline Self-reported good health & 0.135 & 0.118 & $0.394^{* *}$ & 0.146 & $-5.169^{* *}$ & 1.676 \\
\hline No. of health conditions & -0.045 & 0.031 & 0.005 & 0.038 & 0.185 & 0.425 \\
\hline No. of risk factors & -0.068 & 0.049 & 0.038 & 0.053 & 0.377 & 0.687 \\
\hline \multicolumn{7}{|l|}{ Variance explained } \\
\hline Client level & \multicolumn{2}{|c|}{$16.1 \%$} & \multicolumn{2}{|c|}{$41.6 \%$} & \multicolumn{2}{|c|}{$0 \%$} \\
\hline Time level & \multicolumn{2}{|c|}{$3.8 \%$} & \multicolumn{2}{|c|}{$1.3 \%$} & \multicolumn{2}{|c|}{$15.5 \%$} \\
\hline
\end{tabular}

${ }^{*} p<0.05{ }^{* *} p<0.01{ }^{\dagger} p<0.001$.

SE: standard error.

from lower two fifths of socioeconomic disadvantage of many community nursing service clients. This might suggest the need for intervention to address social and environmental factors at the community level. Certainly transport and cost was a major barrier to referral identified by the nurses themselves [33].

Following on from initial assessment and advice, clients who are ready to change need to be linked into longerterm care pathways which support them in changing their risk factors and maintaining them over time. The referral of clients to lifestyle interventions, programs and groups (i.e. Assist, the fourth ' $\mathrm{A}$ ' in the 5As Model) might be a necessary step for many clients to achieve improved health outcomes and reduce risk factors [39,40]. In this study at risk clients infrequently recalled having been referred and other research has identified numerous barriers to referral [41]. The fifth ' $\mathrm{A}$ ', Arrange follow up, is important in the maintenance of behaviour change even over the medium term. Prerequisites for these two actions include adequate availability and affordability of referral services, improved communication, and transfer of care between community health nurses and other providers involved in long-term care. These long-term providers may include the client's GP, private or public allied health professionals, or other community services and programs. Critical to this transfer is clarity about who is prepared to take on the role of coordinating and monitoring the client's lifestyle risk factors over months and years.
There are a number of limitations in the study that need to be acknowledged. The data are based on self-report by clients which may have introduced bias especially for weight. Nurses from the LI (comparison) sites commented that simply answering the initial survey prompted them to be more aware of the need to include addressing lifestyle risk factors in their professional care of their clients (i.e. the Hawthorne effect) [42]. This may account for the improvement in physical activity and diet scores in both groups. This study adopted a quasi-experimental design because it was not feasible to randomise the intervention according to individual clients or practitioners within the services. The overall response rate could also have introduced bias affecting the generalisability of the findings, as more interested clients may have chosen to participate.

\section{Conclusion}

The study demonstrated that an intervention to provide community nurse training and support for management of clients' SNAPW risk factors was associated with increases in advice and referral of clients with risk factors. This was associated with some improvement in client readiness for physical activity. There were no changes, however, in lifestyle behaviours or weight. This suggests a need to facilitate referral to more intensive interventions for clients with risk factors identified by community health nurses and for follow up by providers involved in 
long-term continuing care. This presents a challenge for the community health care sector and to current practices regarding communication and linkage between primary health care and other services in the Australian health care system.

\section{Competing interests}

The authors declare that they have no competing interest in the conduct of this study.

\section{Authors' contributions}

All authors contributed to the study design and reviewed and approved the final manuscript.

\section{Acknowledgements}

The authors wish to acknowledge the former Centre for Health Advancement, NSW Ministry of Health for funding the study. This paper is presented on behalf of the CN SNAP project team which includes: $S$ Buckman, K Partington, A Mitchell, H Smith, J Asquith, R Whittaker, M Hilkmann, C Lisle, K Caines, S Clark, S Dunn, B Christl, M Mangold and R Phillips.

Received: 12 September 2012 Accepted: 16 April 2013 Published: 22 April 2013

\section{References}

1. AlHW: Chronic Disease and Associated Risk Factors in Australia. Canberra: Australian Institute of Health and Welfare; 2006.

2. ABS: National Health Survey: Summary of Results, 2007-08. Canberra: Australian Bureau of Statistics; 2009.

3. Whitlock E, Orleans T, Pender N, Allan J: Evaluating primary care behavioural counseling interventions: an evidence-based approach. Am J Prev Med 2002, 22(4):267-284.

4. Duaso MJ, Cheung P: Health promotion and lifestyle advice in a general practice: what do patients think? J Adv Nurs 2002, 39(5):472-479.

5. Rice $V$, Stead L: Nursing interventions for smoking cessation (review). Cochrane Database Syst Rev 2008, Art.No.(1):CD001188. doi:10.1002/ 14651858.CD001188.pub3.

6. Kaner E, Beyer F, Dickinson H, Pienaar E, Campbell F, Schlesinger C, Heathe $\mathrm{N}$, Saunders J, Burnand B: Effectiveness of brief alcohol interventions in primary care. Cochrane Database Syst Rev 2007, 18(2):CD004148. doi:004110.001002/14651858.CD14004148.pub14651853.

7. Pignone $\mathrm{M}$, Ammerman A, Fernandez $\mathrm{L}$, Orleans $\mathrm{T}$, Pender $\mathrm{N}$, Woolf $\mathrm{S}$, Lohr $K$, Sutton S: Counseling to promote a healthy diet in adults. A summary of the evidnece for the U.S Preventive Services Task Force. Am J Prev Med 2003, 24(1):75-90.

8. Team CP: Evaluation of the counterweight programme for obesity management in primary care: a starting point for continuous improvement. Br J Gen Pract 2008, 58(553):548.

9. Lawton B, Rose S, Elley R, Dowell A, Fenton A, Moyes S: Exercise on prescription for women aged 40-74 recruited through primary care: two year randomised controlled trial. BMJ 2008, 337:a2509.

10. Elley C, Kerse N, Arroll B, Robinson E: Effectiveness of counselling patients on physical activity in general practice: a cluster randomised controlled trial. Br Med J 2003, 326:793-798.

11. Eriksson MK, Franks PW, Eliasson M: A 3-year randomized trial of lifestyle intervention for cardiovascular risk reduction in the primary care setting: the Swedish Björknäs study. PLoS One 2009, 4(4):e5195. doi:10.1371/journal. pone.0005195.

12. Sargeant GM, Forrest $L E$, Parker RM: Nurse delivered lifestyle interventions in primary health care to treat chronic disease risk factors associated with obesity: a systematic review. Obes Rev 2012, 13:1148-1171.

13. Dosh SA, Holtrap JS, Torres T, Arnold AK, Bauman J, White LL: Changing organizational constructs into fucntion tools: an assessment of the $5 A^{\prime}$ s in primary care practices. Ann Fam Med 2005, 3:550-s52.

14. Hung DY, Shelley DR: Multilevel analysis of the chronic care model and the $5 \mathrm{~A}$ services for treating tobacco use in urban primary care clinics. Health Serv Res 2009, 44(1):103-127.
15. Brookes K, Davidson J, Daly P, Hancock K: Community health nursing in Australia: a critical literature review and implications for professional development. Contemp Nurse 2004, 16:195-207.

16. Kemp LA, Harris E, Comino EJ: Changes in community nursing in Australia: 1995-2000. J Adv Nurs 2005, 49(3):307-314.

17. Laws R, Williams A, Powell Davies G, Eames-Brown R, Amoroso C, Harris M: A square peg in a round hole? Approaches to incorporating lifestyle counselling into routine primary health care. Aust J Prim Health 2008, 14(3):101-111.

18. Runciman $\mathrm{P}$, Watson $\mathrm{H}$, Mclntosh J, Tolson D: Community nurses' health promotion work with older people. J Adv Nurs 2006, 55(1):46-57.

19. Ward B, Verinder G: Young people and alcohol misuse: how can nurses use the Ottawa Charter for Health Promotion? Australian Journal of Adcanced Nursing 2008, 25(4):114-119.

20. Smith K, Bazini-Barakat N: A public health nursing practice model: melding public health principles with the nursing process. Public Health Nurs 2003, 20(1):42-48

21. Sourtzi $P$, Nolan $P$, Andrews R: Evaluation of health promotion activities in community nursing practice. J Adv Nurs 1996, 24:1214-1223.

22. Laws RA, Chan BC, Williams AM, Davies GP, Jayasinghe UW, Fanaian M, Harris MF: An efficacy trial of brief lifestyle intervention delivered by generalist community nurses (CN SNAP trial). BMC Nurs 2010, 9(1):4.

23. RACGP: Guidelines for Preventive Activities in General Practice. 7th edition. Melbourne: RACGP; 2009.

24. Smith B, Marshall A, Huang N: Screening for physical activity in family practice: evaluation of two brief assessment tools. Am J Prev Med 2005, 29(4):256-264

25. Bush K, Kivlahan D, McDonell M, Fihn S, Bradley K: The AUDIT alcohol consumption questions (AUDIT-C). Arch Intern Med 1998, 158:1789-1795.

26. CfEa R: Summary Report on Adult Health from the New South Wales Population Health Survey. Sydney: NSW Department of Health; 2008:2009.

27. Marshall AL, Smith BJ, Bauman AE, Kaur S, Bull F: Reliability and validity of a brief physical activity assessment for use by family doctors. British J Sports Medicine 2005, 39(5):294-297.

28. Prochaska J, Velicer W, Rossi J, Goldstein M, Marcus B, Rakowski W, Fiore C, Harlow L, Redding C, Rosenbloom D, et al: Stages of change and decisiona balance for 12 problem behaviors. Health Psychol 1994, 13(1):39-46.

29. Fanaian M, Laws RA, Passey M, McKenzie S, Wan Q, Powell Davies G, Lyle D, Harris MF: Health improvement and prevention study (HIPS) - evaluation of an intervention to prevent vascular disease in general practice. BMC Family Pracice 2010, 11:57.

30. Kerr C, Tayler R, Heard G: Handbook of public health methods. Sydney: McGraw-Hill; 1998.

31. Happ MB, Sereika S, Garrett K, Tate J: Use of the quasi-experimental sequential cohort design in the Study of Patient-Nurse Effectiveness with Assisted Communication Strategies (SPEACS). Contemp Clin Trials 2008, 29(5):801-808.

32. Rashbash J, Steele F, Browne W, Prosser B: Multilevel analysis with MLwiN Software: A user's guide to MLwiN version 2.0.. Bristol: Centre for multileve modelling, University of Bristol; 2005.

33. Chan BC, Laws RA, Williams AM, Davies GP, Fanaian M, Harris MF: Is there scope for community health nurses to address lifestyle risk factors? The community nursing SNAP trial. BMC Nurs 2012, 11(1):4.

34. Christl B, Chan B, Laws R, Williams A, Davies GP, Harris MF: Clients' experience of brief lifestyle interventions by community nurses. Aust J Prim Health 2012, 18(4):321-326.

35. Wadden TA, Volger $S$, Sarwer DB, Vetter ML, Tsai AG, Berkowitz RI, Kumanyika S, Schmitz KH, Diewald LK, Barg R, Chittams J, Moore RH: A two-year randomized trial of obesity treatment in primary care practice. N Engl J Med 2011, 365(21):1969-1979.

36. Wood D, on behalf of the EUROACTION Study Group, et al: Nurse-coordinated multidisciplinary family based cardiovascular disease prevention programme (EUROACTION) for patients with coronary heart disease \& asymptomatic individuals at high risk of cardiovascular disease: a paired cluster-randomised controlled trial. Lancet 2008, 371:1999-2012.

37. Thompson KA, Parahoo AK, Blair N: A nurse-led smoking cessation clinic -- quit rate results and views of participants. Health Educ J 2007, 66:307.

38. Borelli BNS, Hecht J, Edmonds K, Papandonatos G, Abrams D: Home health care nurses as a new channel for smoking cessation treatment: outcomes from project CARES (Community-nurse Assisted Research and Education on Smoking). Prev Med 2005, 41:815-821. 
39. Appel L, Clark JM, Yeh H-C, Wang N-Y, Coughlin JW, Daumit GD, Miller ER, Dalcin A, Jerome GJ, Geller S, Noronha G, Pozefsky T, Charleston J, Reynolds JB, Durkin N, Rubin RR, Louis TA, Brancati FL: Comparative effectiveness of weight-loss interventions in clinical practice. N Engl J Med 2010, 365:1959-1968.

40. Hung DY, Rundall TG, Tallia AF, Cohen DJ, Halpin HA, Crabtree BF: Rethinking prevention in primary care: applying the chronic care model to address health risk behaviors. Milbank Q 2007, 85(1):69-91.

41. Passey ME, Laws RA, Jayasinghe UW, Fanaian M, McKenzie S, Powell-Davies G, Lyle D, Harris MF: Predictors of primary care referrals to a vascular disease prevention lifestyle program among participants in a cluster randomised trial. BMC Health Serv Res 2012, 12:234.

42. Leonard $K$ : Is patient satisfaction sensitive to changes in the quality of care? An exploitation of the Hawthorne effect. J Health Econ 2008, 27:444-459.

doi:10.1186/1471-2458-13-375

Cite this article as: Harris et al:: The impact of a brief lifestyle intervention delivered by generalist community nurses (CN SNAP trial). BMC Public Health 2013 13:375.

\section{Submit your next manuscript to BioMed Central and take full advantage of:}

- Convenient online submission

- Thorough peer review

- No space constraints or color figure charges

- Immediate publication on acceptance

- Inclusion in PubMed, CAS, Scopus and Google Scholar

- Research which is freely available for redistribution 